Article

\title{
Blak, Bi+ and Borderlands: An Autoethnography on Multiplicities of Indigenous Queer Identities Using Borderland Theory
}

\author{
Mandy Henningham \\ Department of Sociology and Social Policy, University of Sydney, Camperdown, NSW 2006, Australia; \\ E-Mail: mandy.henningham@sydney.edu.au
}

Submitted: 5 November 2020 | Accepted: 6 January 2021 | Published: 15 April 2021

\begin{abstract}
Indigenous queer people often experience a conflict in identity, feeling torn between long-standing cultures and new LGBTIQA+ spaces; however, conflicts are being reframed by new generations of Indigenous queer academics who consider decolonising ideas about white heteronormativity. The following autoethnography of my own Indigenous queer journey (muru) uses narrative analysis to explore the challenges of living between worlds as well as the difficulties in gaining acceptance from multiple cultures. This story, like many others, highlights the power of narrative as it reflects the nuanced experiences of Indigenous queer people with identity multiplicity via the application of borderland theory. The narrative analysis forefronts the wide impact of internalised phobias (homophobia, biphobia, and racism) and its impact on performative self-expression of sexual identity, self-sabotage, institutionalized racism and shadeism, and community acceptance, particularly for bi+ sexual identities. This article will explore existing literature which illustrates how navigating the multiplicity of identities may result in poorer social and emotional wellbeing, particularly for Indigenous queer youth. The article concludes with final comments and suggests future directions in mixed method research with Indigenous queer Australians to better understand and improve their social and emotional wellbeing.
\end{abstract}

\section{Keywords}

Aboriginal; borderland theory; Indigenous; internalised homophobia; LGBTIQ; queer; youth

\section{Issue}

This article is part of the issue "Young, Indigenous, LGBTIQ+: Understanding and Promoting Social and Emotional Wellbeing" edited by Karen Soldatic (Western Sydney University, Australia), Linda Briskman (Western Sydney University, Australia), William Trewlynn (BlaQ Aboriginal Corporation, Australia), John Leha (BlaQ Aboriginal Corporation, Australia), Corrinne Sullivan (Western Sydney University, Australia) and Kim Spurway (Western Sydney University, Australia).

(C) 2021 by the author; licensee Cogitatio (Lisbon, Portugal). This article is licensed under a Creative Commons Attribution 4.0 International License (CC BY).

\section{Introduction}

Indigenous queer people often experience a conflict in identity between long-standing cultures and new LGBTIQA+ spaces (Kerry, 2014); however, conflicts are being increasingly reframed as new generations consider decolonising ideas about white heteronormativity. This article reimagines some previous discussions surrounding Indigenous queer identities (Henningham, 2019) via autoethnographic methodology. Furthermore, I also share my own lived experiences through narrative analysis accompanied by reflexive writing to invite readers into the emergent experience of conducting research. This analysis and reflexivity are underpinned by Gee and colleague's definition (as cited in Australian Government, 2017) of social and emotional wellbeing that encompasses mental and physical health for Indigenous peoples - a holistic concept that interweaves the connections between body, mind and emotions, family and kinship, community, culture, country, and spirituality and ancestors.

To provide some background of where I am situated in my identities, I will share my personal muru to learning and living culture, as well as my muru to becoming an Aboriginal queer academic. Building upon this, I explore how Indigenous queer journeys involve conflict 
around sexual and cultural identities using borderland theory (Anzaldúa, 1987). Following this narrative analysis, I will discuss how this relates to existing literature regarding the needs of Indigenous queer youth and conclude with my developing research which aims to contribute to the emerging field of Indigenous Queer studies. To begin, I will address the backgrounds of the ethnographic approaches that underpin the development of this article.

\section{Terminology}

This article most frequently uses the term 'Indigenous peoples' for Australia's First Peoples (or 'Indigenous Australians,' if the term is being discussed in a global context), however, some examined studies use the term 'Aboriginal,' which will be maintained if used by the authors. 'Blak' is an Aboriginal English and Creole word used as an empowering descriptor for my self-identity and is used in various writings by Aboriginal people to reclaim stereotypical, representational, and historical notions of Blackness (Hazel, 2018). I use 'white' not in reference to the literal pigmentation of the skin, but in reference to people who (knowingly or not) are engaged in the racialised social structures they are positioned within. Muru is an Aboriginal word from Dharug language meaning 'roads/path' (Troy, 1994/2019) and is used to reclaim culture amongst otherwise moderately colonialised language and symbolises holding Indigenous knowledges throughout my narratives.

'LGBTIQA+' is an umbrella term for all non-heteronormative sexual, sex, and gender identities; the term is used in this article interchangeably with 'queer,' which may be perceived by some as more inclusive. The term 'bit' is used, as it encapsulates a range of nonmonosexual (not homosexual or heterosexual) identities such as bisexual, pansexual, plurisexual, ambisexual, asexual and other multi-gender attracted identities that experience the romantic or sexual attraction to more than one gender, but not necessarily to the same degree, at the same time, or in the same way (Nelson, 2020). ' $\mathrm{Bi}+$ ' is also used interchangeably with 'non-monosexual' in contexts of the broader monosexual/non-monosexual dichotomy. 'Bisexual' is only used if a referenced study has mentioned this term, as it may not have included other bi+ identities in their research. In reference to my own sexual identity, the terms 'bit' and 'queer' are used interchangeably.

The broader term of 'internalised phobias' is the internalisation of negative attitudes and beliefs and here refers to internalised homophobia, biphobia, or internalised racism. While homophobia and biphobia are sometimes used interchangeably, some contexts exclusively refer to internalised biphobia as it is more specific in conversations surrounding monosexuality/non-monosexuality rather than heterosexuality/homosexuality.

\section{Exploring Narratives}

Narratives are often referred to as a historical and universal concept that transcends, not only disciplines, but societies and cultures globally; "a fundamental operation of the normal mind functioning in society. To learn to speak is to learn to tell a story" (Le Guin, 1989, p. 39). They are used to explore the lived experiences of marginalised groups as it allows for an intimate navigation of experiences that quantitative approaches may not identify.

The purpose of Indigenous (auto)ethnography is to disrupt the power imbalance in research via the narratives of Indigenous voices. This approach challenges the status quo (heteronormative, masculine, white, middleand upper-class research/ers) by rejecting the subjugation of marginalised people and colonised approaches and forefronts one's own cultural and personal stories (Smith, Denzin, \& Lincoln, 2008).

I will also utilise a narrative autoethnographic approach to explore patterns of self-reflection and analysis of existing literature. Reflexivity will be used to illustrate the connection of these thought processes in addition to providing context; it offers reflection and analysis via a personal lens. This subjectivity adds meaningful and emotional depth to the analysis via introspection and 'vignettes' (a vivid portrayal or evocative short story detailing an experience or critical event used as a form of data to highlight a theoretical concept; see Erickson, 1986; Jarzabkowski, Bednarek, \& Lê, 2014), furthering the readers' understanding behind the personal motivations for pursuing this research topic (Ellis, 2004). Layered accounts are formed by questioning and comparing one's own experiences against existing research and theory rather than using the more rigorous grounded theory-based pursuit for 'truth' (Charmaz, 1983).

I wish to acknowledge that I am writing this article from the positioning of someone who identifies as a middle-class, hetero-passing, white-passing, Indigenous queer woman investigating internalised phobias and their impacts in relation to the multiplicity of my own sexual and cultural identities.

\section{Yearning for Identity}

\subsection{Muru to Learning my Indigeneity}

My path to learning about culture has been long and complex. My mother was adopted in infancy and there is limited information on her family history. With no connections to family, country or culture, I have had to learn about my culture through non-traditional methods like websites, courses and books, the whitefella way, a true example of the ongoing impacts of colonialism:

It has been a decade long journey to find cultural acceptance and understanding. I feel like I am both inside and outside my own culture; forever feeling like I am staring at my own culture through the looking 
glass. I feel like a child surrounded by white art curators, scrutinising my every move, waiting for me to touch something.

This experience of cultural rejection or mourning a lack of culture or kinship is not uncommon with other Indigenous peoples who have had taken or adopted family members (like mine) and have subsequently had shattered community and cultural connections, not quite knowing where they come from, with no one to pass on cultural histories, stories, and traditions.

As part of my own cultural muru, I started to attend cultural classes where I can share my story and learn cultural practices and traditions the right way where I can yarn with other Indigenous peoples and share our stories. While it is not the country of my ancestors, it is the country I was born and raised in. I still feel some connection, even if it is not quite the same. It is both a culturally safe space where I can learn and where I can mourn what I never had.

I found that few people had the same story, highlighting the diverse experiences of being an Indigenous Australian. I value every session I have at the centre and feel grateful that there is a space to learn culture the right way, from our people rather than from a book or website which had left me clambering for cultural connection.

\subsection{Muru to Indigenous Queer Research}

Whilst my familial cultural connections are fractured, I am involved and accepted in the Indigenous community at the University of Sydney from my time there teaching and researching the health and wellbeing of intersex populations. I have worked as a teaching fellow and an Indigenous tutor under the Indigenous Tutorial Assistance Scheme (ITAS) working with many Indigenous students of all levels to further their skills in academic development. I am a valued and respected scholar amongst fellow Indigenous staff and have built some amazing relationships working with them on Indigenous research projects. Being accepted into the Indigenous community there helps me feel supported; a notion that has been identified in existing research which highlighted the importance of how building relationships at University is vital to success in higher education for Indigenous Australians (Hill, Winmar, \& Woods, 2018).

I have always been very eager to expand my engagement in other Indigenous communities; it is how I find and foster connection to community as an Indigenous woman who did not get to grow up on country. However, it is difficult to make connections without someone bringing you in. Despite the challenges of this, I persist. I use this sense of resilience to push myself further in my career, as well as using it as a building block to mentor other Indigenous students and researchers.

I have found that the difficulties of cultural acceptance or access is a shared experience amongst many Indigenous Australians, it feels like everyone has a story. Sharing these stories makes us stronger together and builds our collective resilience as a community. Resilience is a strong trait of Indigenous peoples that is required to survive and thrive at university (Hall et al., 2015).

\section{The Borderland Between Indigeneity and Queerness}

\subsection{Holding onto Two Cultures}

The application of borderland theory can offer greater insights into the difficulties of 'identity multiplicity' such as holding both Indigeneity and queer identities. For context, borderland theory grew from the lived experiences of Gloria Anzaldúa and others living between the two cultures of Mexico and the United States of America on the border, navigating the difficulty in holding onto two cultures with power imbalances (Anzaldúa, 1987).

There are similarities between explanations of queer and the borderlands. Callis (2014) explained the diversity within queer itself, how queer does not particularly refer to anything specific; even as an identity and theory, queer is a fluid concept. Similarly, Anzaldúa stated the borderlands is "an unstable, unpredictable, precarious, always-in-transition space lacking clear boundaries" (Anzaldúa, 2009, p. 243). Therefore, queer identities and the borderlands are both defined as being moveable, hard to define, and confine. Borderland theory forefronts identity multiplicity: it can be used to explore the intersectionality between various self-identities including sexual identity, gender identity, Indigeneity, ethnicity, race, and class (Callis, 2014).

For example, the complexities of holding multiple identities such as identifying as queer and Indigenous can be better understood by this model; queer people navigate a heteronormative (western) world not built for them, and Indigenous peoples navigate a colonised world that was imposed upon them. Whilst both are marginalised populations and do not have a lateral power imbalance (despite still experiencing lateral violence), both groups are subjugated by the powers of white heteronormativity. Someone with Indigenous and queer identities may end up navigating four or more borderland communities: mono-sexual/non-monosexual and Indigenous and non-Indigenous. This demonstrates the layered complexities of identity multiplicity.

\subsection{Additional Barriers for Bi+ Identities}

This becomes more layered when looking specifically at those with bi+ identities. Modern interpretation of sexuality is often understood as a monosexist binary between homosexuality and heterosexuality, leaving those with bi+ identities fighting for recognition and inclusion. Callis (2014) used borderland theory to discuss how bi+ identities remain outside of the homosexual/heterosexual binary, fighting to be a part of both communities while navigating the borderland of marginalised homosexual- 
ity and hegemonic heteronormativity. This is a prime example of the struggles bi+ people face as they try to hold onto multiple identities with stark differences in power balances.

Navigating these borderlands is a diverse experience due to the additional subjective contexts (ethnicity, prior sexual identities, age, or marital statuses, etc.) from one's identity multiplicity that influence their lived experiences. Irrespective of this subjectivity, these different pathways can all be considered as having borderland sexualities (Callis, 2014). As such, "each of these people would understand their identities in completely different ways, and not necessarily feel as though they shared any commonalities with one another" (Callis, 2014. p. 70). Hence, it is possible that navigating bi+ sexual identities with pre-existing identity multiplicities may still be an isolating experience, regardless of other bi+ people following the same roads to the borderlands.

These added layers likely contribute to the poorer mental health outcomes of bisexual people due to experiencing invisibility, erasure, biphobia and being 'out' (Taylor, Power, Smith, \& Rathbone, 2019). Bisexual people are more likely to be diagnosed with mental health disorders and engage in self-harm or suicidal thoughts. Taylor et al. (2019) identified higher levels of psychological distress in bisexual people with a total of 58.5\% experiencing high or very high psychological distress compared to $11.7 \%$ of the general population. These overall findings support existing research that bisexual people experience poorer mental health than those who are heterosexual, gay or lesbian (Loi, Lea, \& Howard, 2017; McNair, Kavanagh, Agius, \& Tong, 2005; Persson, Pfaus, $\&$ Ryder, 2015). These statistics are also comparable to Indigenous Australian youth who reported high to very levels of distress, 2.4 times higher than non-Indigenous youth (Australian Institute of Health and Welfare, 2011). While both populations individually experience high levels of distress and poor mental health, this does not reflect the added complexities brought about by an intersectional identity.

\section{Internalised Phobias: A Narrative Analysis}

\subsection{Introducing Internalised Phobias}

If one does 'cross the border' to the other community, there is the threat of being caught and expelled. This occurs when bi+ people are excluded from heterosexual groups as well as being rejected by biphobic queer spaces (Li, Dobinson, Scheim, \& Ross, 2013). This contributes to the affirmation or development of internalised biphobia (Chard, Finneran, Sullivan, \& Stephenson, 2015); never feeling or being accepted as 'queer enough' or feeling like they have something to prove. It is a double-edged sword of both privilege and isolation.

The following personal narrative analyses inspired three epiphanies; understanding the interrelationship between internalised biphobia (and other inwardly directed negative social norms and attitudes) and performative social interactions, the presence of parallel internalised racism when examining these concepts under an Indigenous lens, and the links between internalised biphobia and the yearning for community acceptance.

\subsection{Internalised Phobias and Performative Self-Expression of Identity}

In my own experiences, I feel the same about approaching Indigenous cultural events and queer events; I feel that I am not 'gay enough' for queer communities and feel too disconnected to be accepted into Indigenous Australian communities. How does one project or enact a cultural identity? How do you flag yourself to peers you want to connect with?

Hegde (2002) suggested that enacting and negotiating identity is influential in everyday social interactions and relationships. Therefore, my white-passing skin tones, brightly dyed hair, mannerisms, vernaculars, and mild alternative aesthetics are a moving part of daily social interactions with others that formulate the process of negotiating and renegotiating my various identities; how they are projected and how they are received. I recently had an incidental reflective experience as I watched footage of myself prepare to host a bi+ community meeting called 'I Might be (Bi)as' via an online platform:

I played the video recording of the session. There was eight, long minutes of only myself on the screen as I had logged on and pre-maturely hit record prior to participants' arrivals. I hadn't planned on selfobservation, but the opportunity presented itself. As I peered through the looking glass, she became a distal character before me, unbeknownst to her. I immediately felt vulnerable. Watching yourself waiting alone says more than I ever could have expected. Watching her, I recalled feelings of inadequacy, did I look queer enough to host and facilitate a queer workshop? I saw her obsessively tussle her hair, desperately trying to fluff it up to a more 'queer-friendly' style. I observed her putting on her rainbow earrings. She was repeatedly checking to see if they were visibly rainbow through the webcam, needing to flag her queerness. I began to realise just how fraught my body was with internalised biphobia and the accompanied craving for belonging. She didn't feel queer enough. I never feel queer enough.

My observations of how I negotiated and enacted certain perceived 'queer aesthetics' emphasise the role that doing gender (Butler, 1990) plays in expressing sexual identity. My need for enacting and negotiating my projected identity reflected a desire for acceptance from my peers.

This acknowledgement allowed me to confront the deep fear of rejection experienced from multiple com- 
munities which manifested into the internalised biphobia I held within, a rejection from other communities and a rejection of the self. While I understood the rationality of these fears among monosexual communities and Indigenous communities (i.e., communities I have experienced difficulties accessing/gaining visibility), I had no cause to anticipate rejection from my peers in the bi+ community; we were on 'equal ground' in terms of roaming the borderland seeking acceptance. Why did I not feel queer enough among my own?

General populations often associate sexual identity with the performative nature of one's expressed gendered behaviours (or how one 'does gender') rather than the less visible specific sexual partners. For example, lesbian identities who perform a very feminine expression are often mistaken as heterosexual women. However, some choose to follow a certain style away from 'normative femininity' to self-represent as 'queer femmes,' to use femme to represent queerness for recognition and to fit into queer spaces (McCann, 2018). This gets more complex when considering bi+ identities as living on the borderland of homosexual/heterosexual and feminine/masculine leaves limited space for selfpresentation, and self-expression, and media representation, a contributing factor to bi+ invisibility. Whilst this does make space for playfully combining or recombining varied elements of self-expression across many of these identities/expressions, the lack of clear visible markers for bi+ sexual identities raises questions regarding how to represent one's sexual identity and if others can interpret this representation (Nelson, 2020). This makes performative self-expression or 'doing beauty' (Hammidi \& Kaiser, 1999) challenging for bi+ sexual identities as they struggle to express themselves in a way that does not isolate them from one community/subset of dating experiences or the other (Chmielewski \& Yost, 2013). Further, it takes vigilance to consistently scrutinise one's own behaviours and actions to ensure it is adhering to the cultural norms of a chosen community (Callis, 2014).

This self-scrutiny reaffirms the desire for acceptance and recognition even in one's own peer group. Thus, the presence of internalised bi/homophobia dictates the perceived necessity to gain or shred certain identity performances for acceptance and is so ingrained that bi+ people feel they need to emphasise their identity performance to 'prove' their dedication to queerness, even to appease their own (Callis, 2014). Alternatively, monosexist gender performativity can create pressures to adhere to the safety of social norms prescribed gender binary, perpetuating cisnormal social structures which contributes to a heterosexist and transphobic culture (Nelson, 2020).

\subsection{Internalised Phobias and Indigeneity}

As I am writing this from the perspective of someone with identity multiplicity, I reflected on these same attitudes under the context of indigeneity. Upon reflection,
I am certain I would have been fraught with a parallel panic if other Indigenous queer participants attended; I would have a strong desire to flag my identity as a proud Blak woman, to show that I belong, that I am 'one of us.'

I imagined myself decolonising how I 'did beauty,' like not straightening my curly hair, which I have been socially conditioned by the "imperialist white supremacist capitalist patriarchy" (Hooks, 2000, p. 46) to 'diss-appreciate' in its natural state (Norwood, 2018). Whilst this would be a liberating experience, to free my Indigenous, authentic self and thrust it into visibility, I often withhold the desire out of fear of experiencing shadeism (from non-Indigenous and Indigenous peoples) as a light-skinned Aboriginal woman.

\subsection{Internalised Phobias, Shadeism, and Institutionalised Racism}

Shadeism privileges people of colour with lighter skin tones over those with darker skin tones, granting greater access to employment, housing, and education (Hunter, 2007). This lens demonstrates how "dark-skinned people may be perceived as more racially and culturally authentic than light-skinned people and may therefore be considered desirable additions to workplaces where Aboriginal and Torres Strait Islander presence is a requirement" (Plater, Mooney-Somers, Barclay, \& Boulton, 2020, p. 495). Yet, darker-skinned people are more often ignored or othered by a dominant workplace culture. Often this racism comes in the form of 'soft bigotry' by having low expectations of people of colour and employing them under 'compassion' from white/settler guilt, only to infantilise and exoticise the employee to reclaim white moral authority (Plater et al., 2020; Steele, 2006). As a light-skinned Aboriginal woman, I have a myriad of experiences where I have seen people (including potential employers) doubt or blatantly reject my Indigeneity; I did not present 'authentic' enough for a check-box hire:

I was nervous walking into the nurse's office prior to my operation. We sat down and began to go through some paperwork. We eventually got to the question I always dread: "So, Mandy, are you Aboriginal or Torres Strait Islander?" She asked it whilst not looking up from the form. "Yes." I replied. "Oh!" She paused as her eyes darted from the page. I could feel her eyes scanning me, scrutinising my appearance. "You don't look it at all. Look at your red hair!" "Well, I am," I said assertively. I was tense. Despite my vigilance, it still catches me off guard. It is hard to stay assertive when someone is questioning your identity, your soul. "Okay then....Aboriginal. You're sure?" "Yes!" I repeated, trying not to sound too defensive. She raised her eyebrows in disbelief and continued to fill out the form.

It is instances like these that are firm reminders of the difficulties in even disclosing identity. Most of my racist or 
shadeist experiences have been a result of institutional racism. The above example in a healthcare setting, the general public as a result of colonial education in the Australian school system ("what percentage Aboriginal are you?"), and lateral violence from organisations and places of potential employment.

I have had challenging and traumatic experiences trying to gain legal paperwork for 'official recognition' as an Indigenous person. Further, gathering this 'proof' of my identity has been incredibly invasive and can be personally trauma inducing for myself and my family, as well as being a barrier to gaining employment. Institutions of power (laws, governing bodies, organisations) create 'identified opportunities' yet the requirements for 'qualifying' for a 'proof of Aboriginality' document vastly ignores the challenges faced by those (and there are many) who have a family history of adoption or displacement (like mine); they have set us up to fail.

Analysing these attitudes and behaviours regarding my indigeneity expanded my thinking about other places this may impact my life. I am reminded of work by Gonsiorek (1988) who discussed a common form of 'covert' internalised homophobia where one is accepting one's own identities yet finds ways to self-sabotage one's own efforts. I resonated with this interpretation and applied it to internalised racism which enabled me to recognise it in my own patterns of behaviour, particularly towards career development. I am hesitant to apply for Indigenous-identified roles out of fear of reigniting the traumas over 'official recognition' or the potential for not being taken seriously by academic peers who take a reductionist view and see my appointment as 'special treatment.'

Reflecting on that scenario under a Queer lens, I have similar reservations for queer-identified roles. Heteronormativity dictates that I am a heterosexual, married woman until proven otherwise, as though the institution of hetero-marriage strips me of my queerness and reduces me to heteronormative functionalism. Thus, there is the ever-present concern that I will be perceived a fraud in a queer role. Reflecting on how these are intertwined, it becomes more apparent that the internalisation of dual-wielding oppression is difficult to escape.

\subsection{The Cycle of Internalised Phobias and Yearning for Peer Acceptance}

There appears to be a cyclical nature to internalised phobias and connection-building; how internalisation of constant community rejection builds a greater longing for community acceptance which in turn, impact how we visibly project our sexual identity to others. Despite wanting to flag ourselves to peers, we still hold a sense of community rejection, even from others perceived to be 'like us.' This leads to covert internalised phobia wherein we may self-sabotage potential connections by expecting rejection or focus on 'othering' ourselves due to additional identities. This may be an example of how identity multiplicity can feel isolating even in unity, supporting Callis' (2014) theory how those with identity multiplicity see themselves differently to some cohorts with other dual+ identities.

\subsection{The Duality of Sexual and Racial Minority Stress}

$\mathrm{Bi}+$ people experience antibisexual prejudice, lateral violence within the LGBTIQA+ community, and assumed monosexuality, while LGBTIQA+ people of colour are subject to unique discrimination including racism within LGBTIQA+ communities in conjunction with heterosexism from their racial/ethnic community (Meyer, 2003). These negative experiences are often referred to as sexual/racial minority stress.

Clark (2014) discussed their own experiences of disclosing sexuality or race; people had asked them about difficulties of being both queer and Aboriginal or had even questioned that people like them exist. The very questioning of both identities signals the idea that being queer and being Aboriginal are incompatible cultures, yet, Aboriginal Australia has a queer history. Baylis (2015) examined how gender and sexual diversity of Indigenous peoples is scarcely mentioned in Australian histories which reinforces the hetero-centric literature surrounding historic Aboriginal cultures. Despite this, more recent research suggested that sistergirls (Indigenous transfemme identity identities falling outside western gender binaries) have long been a part of Aboriginal communities since before colonisation (Riggs \& Toone, 2017).

Like Clark (2014), I too am met with intrigue at either my race or sexuality, sitting 'on the fence' of both; a light-skinned Aboriginal woman disconnected from culture who is navigating subjective lived experiences of bierasure. I recall a difficult but powerful memory from a yarning circle about totem animals:

We were going around the circle, discussing our totem animals. I felt so anxious, how would I know that I picked my totem the 'right way'? Will my totem animal be accepted? Will people doubt my indigeneity? Everyone told a beautiful story of connecting with a native animal, until it was my turn. "I know that mine is a bit controversial," I started "but please hear me out. My totem animal is a fox. I know! But fox is here. Fox didn't ask to be here, no knowledge of their origin, trying to adapt to a land they are not naturally acclimatised to. Fox is disliked everywhere for being a pest, but fox didn't ask to be here. Ruining native wildlife, upsetting farms.... But fox is just trying to survive in a world not built for them. I am fox." I gestured towards my red, fox-like hair. There was a silence as everyone processed my totem. Finally, someone said: "I've never liked foxes. They've always gotten to my chickens and I never saw them as anything but a feral pest. But what you said, just now, that's given me a new perspective. I never thought about foxes that way, it's not their fault, they didn't ask for this....Thank you." 
This vignette illustrates the difficulty of identity multiplicity; torn between worlds, I am forever living on the borderland of Indigenous ways and whitefella ways, but never truly either. Similarly, monosexist hegemony gatekeeps me from finding belonging in some heterosexual and queer spaces.

Stories of marginalisation towards multiple identities is also expressed in the artworld. Rea is a Gamilaroi/ Wailwan photographer/digital media, and installation artist who conceptualises the internalised racism and homophobia experienced by many Indigenous queer people, or 'blak kweers' (Bartleme, 2000). Rea's work invites viewers to re-evaluate their own positioning in the multiplicities of race, power, sexuality. As both Indigenous and queer people have a history of being vilified, her series rea-code 1998 featured targets as symbolism. Further, she disrupts assumptions of Indigenous female sexuality by inserting herself into her works to illustrate taking back control, no longer the subject of the western gaze (Bartleme, 2000). The power of her pieces illustrates the multiple ways one can tell a narrative in a way that is meaningful to both artist and audience which may invite a different audience.

Clark's (2014), Rea's (Bartleme, 2000), and my own experiences are subjective but not isolated incidents; there is power in the collection of narratives, and I share my stories in this article to reflect the diversity of experiences had by Indigenous queer people. Clark (2014) discussed how there are various Indigenous queer narratives, yet people are still not listening to them; a blind eye turned to the multiplicities of culture, lived experiences, and community.

Navigating my queerness is not unlike discovering my cultural/ethnic journey. My biological makeup and my presenting mono-cis-het relationship status does enable me to retain white-hetero-monogamous privilege which does assist in protecting myself from certain discriminations or unsafe scenarios under white, and 'bisexual privilege'; having an other-sex partner allows for the freedom of a bi+ identity within the parameters of hegemonic hetero-safety (Anderson \& McCormack, 2016). However, by striving to hold on to both communities, people who identify as bi+ often experience rejection from both (Callis, 2014). Living between polarising identities may result in one or often both communities misreading one's identity, leaving bi+ people invisible or 'twice-rejected' from a community for presenting either 'too straight' or 'too queer' (Shokeid, 2002).

Historically, the queer community has struggled to welcome Indigenous voices in Australia, which is also reflected in Queer theory as it often fails to recognise how some Queer theories and histories once originated from the colonial and violent epistemologies (Clark, 2014). For example, Clark (2014) discussed commentary surrounding the inclusion of a gay character on Aboriginal television show, Redfern Now. Comments about the character sparked online debates on what is and is not 'real' Aboriginal culture in terms of accepting queerness.
The arguments made about Redfern Now supported the tenet that Aboriginal culture either ties a person to the savagery and conservatism on one end of the spectrum (barbarism comments including how ancestors would 'have their heads' for it), and 'civilisation' or western acceptance of sexual diversity on the other (that accepting homosexuality is a western idea, that you 'enjoy being western'). This highlighted the issues surrounding what it means to be 'authentically' Aboriginal and further reiterated the perceived 'incompatibility' of queer and Aboriginal cultural identities, creating a cultural borderland.

\section{Conclusion}

\subsection{Final Thoughts}

By using reflexivity while analysing my subjective narratives, I have grown my understanding of broader cultural experiences (Ellis, Adams, \& Bochner, 2011) both personally, and academically via connecting these reflections with theory.

On a personal level, I discovered that the internalised biphobia I carried with me had such a strong impact on my outwardly projected self-expression of my identity. Further, these same principles uncovered internalised racism which I did not realise was present. It manifested as an enabler of self-sabotage, acting as a barricade to accessing Indigenous specific roles or services which I was sure I would be rejected from; I actively had been othering myself from my own communities due to the negative experiences I had from various institutions of power.

The findings from the narrative analysis and literature suggest that internalised phobias are, in my own experiences, contribute towards fears of rejection due to our often marginalised identities. There is a desire to 'prove one's queerness' as a result, to adjust one's performative identity accordingly for specific communities. This is particularly true for bi+ identities who remain invisible on the dichotomous masculine/feminine scale of doing gender. It drove the need for enacting and negotiating my projected identity, particularly as both my blakness and queerness are invisible. As internalised phobias are the internalisation of constant community rejection, it fosters a greater desire for belonging which may then inform our choices surrounding the performative self-expression of sexual identity.

Therefore, there is a clear, cyclical impact of internalised phobias on how we perceive ourselves and our expectations on being perceived; a desire for community acceptance is born and fostered by performative self-identity expression, only to self-sabotage our efforts by othering ourselves from other identity, and out of fear of rejection. This cements the cycle of rejection and isolation felt by those who experience identity multiplicity, including Indigenous queer people. The cyclical nature of this social exclusion directly impacts social and emotional wellbeing. 
Having a plurality of identities has had a strong impact on my social and emotional wellbeing as an Indigenous queer woman. While I have made some community connections at the University, I am still disconnected from my country and from my unknown family as a direct result of colonialism and assimilation. With my paleness mistaken for whiteness and my romantic relationships passing for heteronormativity, I often feel invisible, roaming the borderland, unseen and alone with no scripts or visual markers to signal my peers.

My lived experiences demonstrate the interconnectedness of all aspects (body, mind, emotions, family, kinship, community, culture, country, spirit, and ancestors; see Australian Government, 2017) of social and emotional wellbeing. Despite the social and emotional isolation explored in this narrative, I acknowledge that my experiences come from a place of privilege as a whitepassing, hetero-passing educated woman.

As my story is just one detailed account of a lived experience of existing on the fringe of multiple identities, it is essential to broaden the scope to wider literature to gain a greater understanding of the interrelationship between plural identities, social and emotional wellbeing in the context of Indigeneity, queerness, and youth.

\subsection{Identified Problems in and for Further Research}

These interrelated concepts strongly impact the social and emotional wellbeing of this population, which young people may be particularly vulnerable to experiencing. Suicide affects $95 \%$ of Indigenous peoples either directly or within close generations (Korff, 2019). Indigenous Australia has the second highest youth suicide rate in the world, twice the rates of overall Australians. In 2017, suicide was the primary cause of death for $40 \%$ of Indigenous Australian youth aged 5-17 years (Dudgeon et al., 2018). The death toll from suicide in Indigenous Australians is rising: 169 Indigenous Australians were victims of suicide in 2018, up from 140 deaths in 2012 (Korff, 2019). Statistics from 2013 showed that suicide is most common in young Indigenous men (aged 25-29), four times the rate for non-Indigenous men (Dudgeon et al., 2018). This often occurs after long durations of suppressed rage from being in powerless positions, enduring the ongoing impacts of colonisation (Korff, 2019).

Intergenerational trauma is another contributing factor, with Indigenous peoples being victims of child abuse from foster parents as well as being subjected to forced removal from their homes and country; this is often compounded with years of institutionalised racism and poverty, building multiple traumas over time. These traumas are passed on either collectively or transgenerationally and can lead to a sense of hopelessness (Korff, 2019). Indigenous elders have identified other factors that contribute to high suicide rates in Indigenous youth such as low self-esteem, the isolation of youth from family disconnection, and a lack of cultural resilience and cross-cultural confusion.
When looking at the needs of minorities within minorities like Indigenous queer youth, there is a greater need for more representation on mental health and suicide prevention forums (Korff, 2019). Whilst data for Indigenous queer youth in Australia is scarce, data from North America found high levels of physical and sexual abuse, high usage of mental healthcare services, suicide risk, and severe poverty in Indigenous LGBTIQ people (Ristock, Zoccole, \& Passante, 2011).

More work needs to be done to improve the mental health of Indigenous queer youth to improve suicide prevention, contributing to their overall social and emotional wellbeing. This social and emotional wellbeing extends to social relationships, family dynamics, romantic and sexual relationships, community experiences, and school experiences.

A 2010 Australian study on LGBTIQ youth found 3\% were Indigenous Australians which reflected the broader Indigenous Australian population figures (Hillier et al., 2010). Indigenous Australian students were less likely to finish their schooling and less likely to reside in their family homes than the wider LGBTIQ youth population (Hillier et al., 2010). This stressed an intersectional barrier to education and stability for Indigenous queer youth in Australia.

Further literature found that bi-erasure and bullying is widespread in Australian schools (Jones \& Hillier, 2016). A Canadian study advocated a two-spirit antibullying model which incorporated a range of queer identities in a fluid, cyclical approach rather than a colonial and dichotomous one (Robinson, 2014). Perhaps this approach could be appropriately considered in a local context.

Given the high rates of suicide in both queer youth populations and Indigenous Australian youth, it can be hypothesised that the triangulation of these identities would experience very high incidences of depression and suicide ideation amongst the Indigenous queer community. Working with this community in a qualitative capacity may identify some factors surrounding depression and suicide ideation which may then inform suicide research.

These alarming statistics reiterate the imperative need for more research-informed resources surrounding the wellbeing, support and harm-minimisation needed amongst this intersectional population.

\subsection{Research in Development}

With my combined research history in marginalised populations (Indigenous students and LGBTIQA+ populations), I aim to combine these research areas to work with Indigenous queer youth. My work aims to explore their lived experiences in; schools, healthcare systems, identity-based communities, social, platonic, and romantic relationships to gain a more comprehensive understanding of what it means to be an Indigenous queer young person. This will be used to identify the needs of young Indigenous queer people; to evaluate how they 
can be better supported in their multiple communities such as school systems, healthcare, and community and peer support.

Further, the findings may produce data surrounding the contributing factors of self-harm and suicide for Indigenous queer youth. Whilst there is research on the broader queer, and trans and gender diverse populations in Australia, the specific needs of populations with intersectional identities like Indigenous queer young people are imperative. There is a great need to address the potential cultural conflicts, exclusion, racism and homo/bi/transphobia, and high rates of self-harm and suicide that is experienced by this community.

The study being developed will use borderland theory and Queer theory to gain an in-depth understanding of Indigenous queer youth lived experiences using diverse methods and methodologies. A Queer Indigenous lens reframes colonialism as a system of racialised heteronormativity; to challenge the status quo via a critical framework (Hames-García, 2013). Specific methods may include traditional methods of quantitative and qualitative data via surveys and interviews (yarn-ups), and content analysis of Indigenous queer content online. Ethnographic methodologies will be employed for deeper insights, such as conducting fieldwork at Indigenous queer events, and other communitybased participatory research approaches such as photovoices (Nykiforuk, Vallianatos, \& Nieuwendyk, 2011) or other artworks.

Additionally, community autoethnographies combine personal experiences of researchers and working alongside communities to identify how a community develops certain cultural or social issues (Toyosaki, Pensoneau-Conway, Wendt, \& Leathers, 2009). This facilitates an environment for further community-building research practices and offers a collective space for sociocultural intervention (von Kardorff \& Schönberger, 2010). By allowing space for different research methods, the study may be more inviting to additional potential participants who prefer more creative ways (rather than written or spoken) of telling their narrative.

Several academics across Australia are pioneering the new field of Indigenous Queer studies, drawing on intersections of new queer ideas with the world's oldest cultures to look at contemporary problems. It is an exciting time in research to be contributing to this emerging field, especially for Indigenous and queer academics alike across an array of disciplines.

\section{Acknowledgments}

I would like to acknowledge and thank those who participated in the bi+ event 'I Might be (Bi)as' and who had the courage to share their stories with me.

\section{Conflict of Interests}

The author declares no conflict of interests.

\section{References}

Anderson, E., \& McCormack, M. (2016). Bisexuality as a unique social problem. In E. Anderson \& M. McCormack (Eds.), The changing dynamics of bisexual men's lives. Focus on sexuality research (pp. 49-67). New York, NY: Springer International Publishing.

Anzaldúa, G. (1987). Borderlands/La Frontera. San Francisco, CA: Aunt Lute Books.

Anzaldúa, G. (2009). (Un)natural bridges, (un)safe spaces. In A. Keating (Ed.), The Gloria Anzaldúa reader (pp. 243-248). Durham, NC: Duke University Press.

Australian Government. (2017). National strategic framework for Aboriginal and Torres Strait Islander Peoples' mental health and social and emotional wellbeing 2017-2023. Canberra: Australian Government.

Australian Institute of Health and Welfare. (2011). Young Australians: Their health and wellbeing 2011. Canberra: AlHW.

Bartleme, E. (2000). Multiple realities: Digital imaging and contemporary queer art. Photofile, 60, 22-25.

Baylis, T. (2015). Introduction: Looking in to the mirror. In D. Hodge (Ed.), Colouring the rainbow. Blak Queer and trans perspectives: Life stories and essays by first nations people of Australia (pp. 1-18). Adelaide: Wakefield Press.

Butler, J. (1990). Gender trouble: Feminism and the subversion of identity. New York, NY: Taylor \& Francis.

Callis, A. S. (2014). Bisexual, pansexual, queer: Nonbinary identities and the sexual borderlands. Sexualities, 17(1/2), 63-80.

Chard, A., Finneran, C., Sullivan, P., \& Stephenson, R. (2015). Experiences of homophobia among gay and bisexual men: Results from a cross-sectional study in seven countries. Culture, Health \& Sexuality, 17(10), 1-16.

Charmaz, K. (1983). Loss of self: A fundamental form of suffering in the chronically ill. Sociology of Health \& Illness, 5(2), 168-195.

Chmielewski, J. F., \& Yost, M. R. (2013). Psychosocial influences on bisexual women's body image: Negotiating gender and sexuality. Psychology of Women Quarterly, 37(2), 224-241.

Clark, M. (2014). Against authenticity CAL-connections: Indigenous queer identities. Overland, 215, 230-236.

Dudgeon, P., Ring, I., Leyendekkers, G., McClintock, K., Lawson-Te Aho, K., King, M., . . . Stoor, J. (2018). Global overview: Indigenous suicide rates. Perth: University of Western Australia.

Ellis, C. (2004). The ethnographic I: A methodological novel about autoethnography. Lanham, MD: AltaMira Press.

Ellis, C., Adams, T., \& Bochner, A. (2011). Autoethnography: An overview. Forum: Qualitative Social Research, 12(1), 1-18.

Erickson, F. (1986). Qualitative methods in research on teaching. In M. C. Wittrock (Ed.), Handbook of 
research on teaching (3rd ed., pp. 119-161). New York, NY: Macmillan.

Gonsiorek, J. C. (1988). Mental health issues of gay and lesbian adolescents. Journal of Adolescent Health Care, 9(2), 114-122.

Hall, L., Maughan, C., Wilkes, M., Thorpe, T., Forrest, J., \& Harrison, A. (2015). Swimming not drowningResilience as a key determinant of success for Aboriginal and Torres Strait Islander pre-tertiary students. Journal for Multicultural Education, 9(3), 159-173.

Hames-García, M. (2013). What's after Queer theory? Queer ethnic and Indigenous studies. Feminist Studies, 39(2), 384-404.

Hammidi, T. N., \& Kaiser, S. B. (1999). Doing beauty. Journal of Lesbian Studies, 3(4), 55-63.

Hazel, Y. (2018). Bla(c)k lives matter in Australia. Transition, 126(1), 59-67.

Hegde, R. S. (2002). Translated enactments: The relational configurations of the Asian Indian immigrant experience. In J. N. Martin, T. K. Nakayama, \& L. A. Flores (Eds.), Readings in intercultural communication: Experiences and contexts (pp. 259-266). New York, NY: McGraw-Hill.

Henningham, M. (2019). Still here still queer, still invisible. In T. Jones (Ed.), Bent Street 3: Australian LGBTIQA+ arts, writing and ideas (pp. 98-105). Melbourne: Clouds of Magellan Publishing.

Hill, B., Winmar, G., \& Woods, J. (2018). Exploring transformative learning at the cultural interface: Insights from successful Aboriginal university students. The Australian Journal of Indigenous Education, 49(1), 2-13.

Hillier, L., Jones, T., Monagle, M., Overton, N., Gahan, L., Blackman, J., Mitchell, A. (2010). Writing themselves in 3: The third national study on the sexual health and wellbeing of same-sex attracted and gender questioning young people. Melbourne: Australian Research Centre in Sex, Health and Society. Retrieved from https://www.glhv.org.au/sites/default/files/wti3_ web_sml.pdf

Hooks, B. (2000). Feminism is for everybody: Passionate. Boston, MA: South End Press.

Hunter, M. (2007). The persistent problem of colourism: Skin tone, status, and inequality. Sociology Compass, 1(1), 237-254.

Jarzabkowski, P., Bednarek, R., \& Lê, J. K. (2014). Producing persuasive findings: Demystifying ethnographic textwork in strategy and organization research. Strategic Organization, 12(4), 274-287.

Jones, T., \& Hillier, L. (2016). The erasure of bisexual students in Australian education policy and practice. In M. Pallotta-Chiarolli (Ed.), Bisexuality in education: Erasure, exclusion and the absence of intersectionality (pp. 51-71). London: Routledge.

von Kardorff, E., \& Schönberger, C. (2010). Evaluationsforschung [Evaluation research]. In G. Mey \& K. Mruck (Eds.), Handbuch qualitative forschung in der psychologie [Handbook of qualitative research in psy- chology] (pp. 367-381). Wiesbaden: VS Verlag and Springer.

Kerry, S. (2014). Sistergirls/brotherboys: The status of Indigenous transgender Australians. International Journal of Transgenderism, 15(3/4), 173-186.

Korff, J. (2019). Aboriginal suicide rates. Creative Spirits. Retrieved from https://www.creativespirits.info/ aboriginalculture/people/aboriginal-suicide-rates

Le Guin, U. (1989). Dancing at the edge of the world. New York, NY: Harper \& Row.

Li, T., Dobinson, C., Scheim, A., \& Ross, L. (2013). Unique issues bisexual people face in intimate relationships: A descriptive exploration of lived experience. Journal of Gay \& Lesbian Mental Health, 17(1), 21-39.

Loi, B., Lea, T., \& Howard, J. (2017). Substance use, mental health, and service access among bisexual adults in Australia. Journal of Bisexuality, 17(4), 400-417.

McCann, H. (2018). Beyond the visible: Rethinking femininity through the femme assemblage. The European Journal of Women's Studies, 25(3), 278-292.

McNair, R., Kavanagh, A., Agius, P., \& Tong, B. (2005). The mental health status of young adult and mid-life nonheterosexual Australian women. Australian and New Zealand Journal of Public Health, 29(3), 265-271.

Meyer, I. H. (2003). Prejudice, social stress, and mental health in lesbian, gay, and bisexual populations: Conceptual issues and research evidence. Psychological Bulletin, 129(5), 674-697.

Nelson, R. (2020). 'What do bisexuals look like? I don't know!' Visibility, gender, and safety among plurisexuals. Journal of Sociology, 56(4). https://doi.org/ $10.1177 \% 2 F 1440783320911455$

Norwood, C. (2018). Decolonizing my hair, unshackling my curls: An autoethnography on what makes my natural hair journey a Black feminist statement. International Feminist Journal of Politics, 20(1), 69-84.

Nykiforuk, C. I., Vallianatos, H., \& Nieuwendyk, L. M. (2011). Photovoice as a method for revealing community perceptions of the built and social environment. International Journal of Qualitative Methods, 10(2), 103-124.

Persson, T., Pfaus, J., \& Ryder, A. (2015). Explaining mental health disparities for non-monosexual women: Abuse history and risky sex, or the burdens of non-disclosure? Social Science \& Medicine, 128, 366-373.

Plater, S., Mooney-Somers, J., Barclay, L., \& Boulton, J. (2020). Hitting the white ceiling: Structural racism and Aboriginal and Torres Strait Islander university graduates. Journal of Sociology, 56(3), 487-504.

Riggs, D., \& Toone, K. (2017). Indigenous Sistergirls' experiences of family and community. Social Work, 70(2), 229-240.

Ristock, J. L., Zoccole, A., \& Passante, L. (2011). Aboriginal Two-Spirit and LGBTQ migration, mobility, and health research project (Final Report). Vancouver: 2Spirits. Retrieved from http://www.2spirits.com/PDFolder/ 2011\%20Vancouver\%20full\%20report\%20final.pdf 
Robinson, M. (2014). 'A hope to lift both my spirits': Preventing bisexual erasure in Aboriginal schools. Journal of Bisexuality, 14(1), 18-35.

Shokeid, M. (2002). You don't eat Indian and Chinese food at the same meal: The bisexual quandary. Anthropological Quarterly, 75(1), 63-90.

Smith, L. T., Denzin, N. K., \& Lincoln, Y. S. (Eds.). (2008). Handbook of critical and indigenous methodologies. Thousand Oaks, CA: Sage.

Steele, S. (2006). White guilt: How Blacks and Whites together destroyed the promise of the civil rights era. New York, NY: HarperCollins.
Taylor, J., Power, J., Smith, E., \& Rathbone, M. (2019). Bisexual mental health: "Findings from the 'who I am' study." Australian Journal of General Practice, 48(3), 138-144.

Toyosaki, S., Pensoneau-Conway, S. L., Wendt, N. A., \& Leathers, K. (2009). Community Autoethnography: Compiling the personal and resituating whiteness. Cultural Studies $\leftrightarrow$ Critical Methodologies, 9(1), 56-83.

Troy, J. (2019). The Sydney language. Canberra: Aboriginal Studies Press. (Original work published 1994)

\section{About the Author}

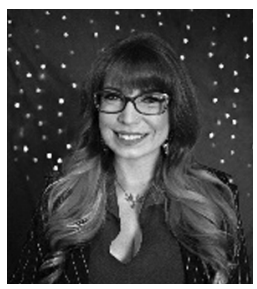

Mandy Henningham (PhD) is an Indigenous woman living on Dharug country in NSW, Australia. She is currently a Research Fellow at the University of Sydney where she is a dedicated LGBTIQA+ advocate and researcher in sexuality, sexual health, Indigenous studies, Intersex studies, youth, and mental health in the Department of Sociology and Social Policy, Faculty of Arts and Social Sciences. 